\title{
EDUARDO GALANTE, DOCTOR HONORIS CAUSA POR LA UNIVERSIDAD NACIONAL DE PIURA (PERÚ)
}

\section{José Luis Casas Martinez}

INSTITUTO DE INVESTIGACIÓN CIBIO

El 14 de enero de 2005 la Universidad Nacional de Piura (Perú) otorgó el Grado Académico de Doctor Honoris Causa al Dr. Eduardo Galante Patiño, director del Centro Iberoamericano de la Biodiversidad (CIBIO), en reconocimiento a su labor de defensa de la biodiversidad y conservación de la Flora y Fauna y ser un destacado defensor del Medio Ambiente.

El solemne acto académico se celebró en el Auditorio Manuel Moncloa y Ferreira del campus universitario y estuvo presidido por el Rector de dicha Universidad, Profesor Edwin Vegas Gallo, habiendo actuado como padrino el Dr. Manuel Gálvez Paredes quien realizó una semblanza de la trayectoria científica y de la actividad en defensa del medio ambiente del nuevo Doctor Honoris Causa.

El Profesor Eduardo Galante licenciado en Ciencias Biológicas por la Universidad de Salamanca en 1975, obtuvo el grado de doctor en Biología por la misma Universidad en 1978 y desde 1991 es catedrático de Zoología de la Universidad de Ali-

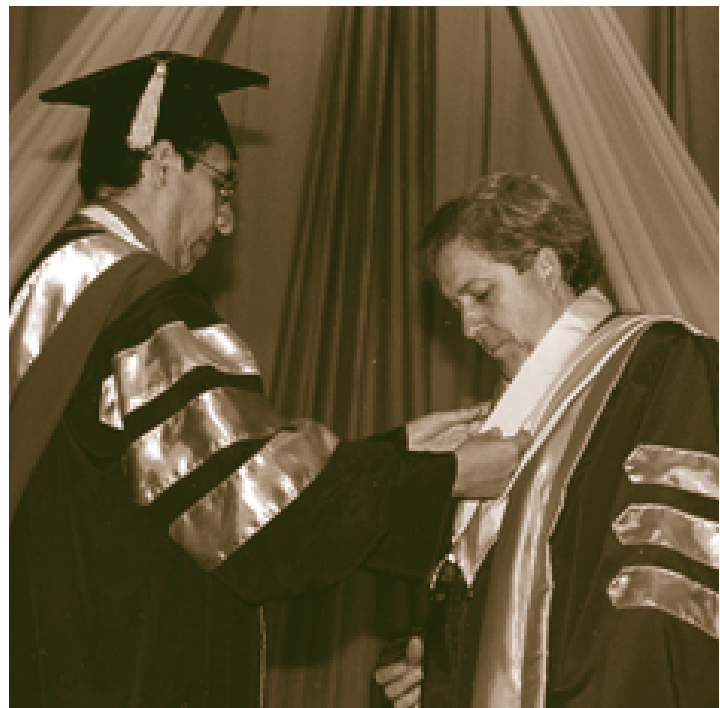

cante. Tiene una extensa producción científica con más de cien publicaciones sobre diversidad entomológica y conservación, y es Presidente del Comité español de Unión Mundial para la Conservación 
de la Naturaleza (UICN) y Presidente de la Asociación española de Entomología.

Su conocida actividad en el campo de la conservación del medio ambiente le ha llevado a formar parte de numerosas Comisiones nacionales e internacionales sobre aspectos relacionados con esta disciplina. Toda esta actividad la ha complementado con la organización de numerosas jornadas, talleres, reuniones y seminarios sobre Conservación de Biodiversidad con una especial proyección en Iberoamérica.

Por otra parte, el Dr. Galante ha impulsado la puesta en marcha de proyectos de cooperación con las poblaciones indígenas que viven en áreas de interés para la conservación de la biodiversidad como un medio que permite aportar las necesarias herramientas para lograr un desarrollo digno de estos grupos sociales en el marco de un desarrollo sostenible.

Toda esta actividad le valió al Prof. Eduardo Galante la distinción en el año 2003 del Premio de Protección del Medio Ambiente de la Junta de Castila y León, habiendo sido ahora en enero de 2005 la Universidad Nacional de Piura la que le ha distinguido con su Doctorado Honoris Causa por su destacada labor profesional y académica en el campo de la conservación de la Naturaleza, por su extensa producción científica y el trabajo realizado en relación con Iberoamérica. 